\title{
HANNAH ARENDT: NÃO SUPORTAR O MAL
}

\author{
HANNAH ARENDT: NOT SUPPORT THE EVIL \\ HANNAH ARENDT: NO APOYAR AL MAL
}

Silvana de Souza Ramos ${ }^{\mathrm{I}}$

RESUMo O artigo pretende analisar as reflexões arendtianas a respeito do mal, especial-
mente as encontradas em trabalhos em que a autora discute os desafios para a ação e o
pensamento autônomo sob regimes políticos autoritários. Minha intenção é apresentar as
consequências da experiência totalitária para a nossa compreensão da responsabilidade
moral, quando se abre uma lacuna entre o passado e o presente, ou seja, quando surge um
abismo que nos separa da tradição. Segundo Arendt, tanto o totalitarismo quanto os crimes
realizados sob sua égide não encontram precedente ou nome registrados na história ou no
pensamento. À luz de tal condição, o pensamento tradicional por si só não permite entender
o significado de eventos e de ações no mundo moderno. Assim, com a ajuda de Arendt, o
artigo tenta ler ambos, eventos e ações, porque eles são o único suporte capaz de orientar o
pensamento de modo que se possa dar nome à experiência moderna do mal.
PALAVRAS-CHAVE: HANNAH ARENDT; ToTALITARISMO; MAL; AÇÃO; PENSAMENTO; RESPONSABILIDADE.

Abstract The article intends to analyze the Arendtian reflections on evil, especially those found in works in which the author discusses the challenges for action and autonomous thinking under authoritarian political regimes. My intention is to present the consequences of the totalitarian experience for our understanding of moral responsibility, when a gap is opened between the past and the present, that is, when there is an abyss that separates us from tradition. According to Arendt, both, totalitarianism and the crimes committed under its aegis, have no precedent or name recorded in history or thought. In the light of such a condition, traditional thinking alone does not allow us to understand the meaning of events and actions in the modern world. Thus, with the help of Arendt, the article attempts to read both, events and actions, because they are the only support capable of guiding thought so that the modern experience of evil can be named.

Key-words: Hannah Arendt; Totalitarianism; Evil; Acting; Thinking; Responsibility.

Universidade de São Paulo (USP), São Paulo/SP - Brasil 
RESUMEN El artículo pretende analizar las reflexiones arendtianas sobre el mal, especialmente las encontradas en trabajos en que la autora discute los desafíos para la acción y el pensamiento autónomo bajo regímenes políticos autoritarios. Mi intención es presentar las consecuencias de la experiencia totalitaria para nuestra comprensión de la responsabilidad moral, cuando se abre una brecha entre el pasado y el presente, o sea, cuando surge un abismo que nos separa de la tradición. Según Arendt, tanto el totalitarismo y los crímenes realizados bajo su égida no encuentran precedente o nombre registrados en la historia o en el pensamiento. A la luz de tal condición, el pensamiento tradicional por sí solo no permite entender el significado de eventos y de acciones en el mundo moderno. Así, con la ayuda de Arendt, el artículo intenta leer ambos, eventos y acciones, porque ellos son el único soporte capaz de orientar el pensamiento de modo que se pueda dar nombre a la experiencia moderna del mal.

Palabras clave: Hannah Arendt; Totalitarismo; Mal; Acción; Pensamiento; ResponsaBILIDAD.

\section{ReSPONSABILIDAdE POLÍTICA E RESPONSABILIDADE PESSOAL}

Hannah Arendt não escreveu um tratado a respeito de ética, e é importante ter em mente que suas reflexões a respeito do agir e do pensar estão ligadas à leitura dos principais eventos que marcaram o século XX - em especial, do totalitarismo, e, ainda, das consequências éticas e políticas trazidas por sua instauração. Assim, é preciso compreender que, em linhas gerais, a emergência de um novo tipo de regime, o qual possibilitou, sem dúvida, o surgimento de um novo tipo de crime - os assassinatos em massa ocorridos durante a vigência do nazismo na Alemanha e do stalinismo na URSS - e, em particular, o posterior julgamento dos burocratas do regime nazista estão, ambos, no centro das reflexões de Arendt sobre o colapso moral da modernidade. Espalhadas por diversos momentos de sua obra, essas reflexões tentam dar conta de uma experiência do mal sem precedentes na história.

Exemplo disso, o livro Responsabilidade e Julgamento é uma das coletâneas feitas com os últimos textos escritos por Arendt, antes da sua morte, ocorrida em dezembro de 1975. São palestras, aulas e conferências feitas nos últimos anos de sua vida, encontradas em seu escritório. O livro reúne as reflexões sobre responsabilidade realizadas pela autora depois da publicação de Eichmann em Jerusalém. Um relato sobre a banalidade do mal, livro de 1963. O relato do julgamento de Eichmann já colocava em questão novas temáticas que não tinham sido abordadas em trabalhos anteriores, como o caráter banal dos crimes nazistas, assunto que não aparecia em Origens do Totalitarismo, obra publicada em 1951. Nos textos de Responsabilidade e Julgamento, a autora continua a meditar a respeito do fenômeno totalitário no intuito de compreender o mal engendrado por este.

$\mathrm{Se}$, na modernidade, fenômenos inéditos desafiam o pensamento, de modo que a perda da tradição é idêntica à perda da sabedoria por parte dos homens e das mulheres, as reflexões sobre a ética devem criar ou reinventar conceitos para superar concepções inadequadas. Sem cessar de se referir de alguma forma ao passado e à tradição, tais reflexões devem, contudo, 
construir uma filosofia guiada por tais fenômenos e, ao mesmo tempo, comprometida com o desafio de compreendê-los. Ademais, segundo atestam muitos de seus leitores, Arendt não se preocupa apenas com o desafio teórico imanente a essa busca por compreensão, pois se trata também de tentar deter o avanço da novidade totalitária, cuja "terrificante originalidade [...] não se refere a uma nova 'ideia' que apareceu no mundo, mas a atos em ruptura com toda a nossa tradição" (SOUKI, 2006, p. 44), atos cuja monstruosidade fez romper, em suma, o próprio pensamento moral, "não por ideias filosóficas, mas pelos fatos políticos do século XX", de tal modo que a tradição "não podia ser restaurada" (KOHN. In: ARENDT, 2004, p. 11).

Ora, os julgamentos dos crimes nazistas trouxeram à tona a questão da iniciativa individual no interior do sistema burocrático totalitário, o qual tentava impedir qualquer ato espontâneo, isto é, qualquer ação que não estivesse ancorada em ordens superiores. As investigações e os relatos colhidos, tanto pela defesa quanto pela acusação desses agentes, mostravam, contudo, que a realidade de muitos dos crimes dependia de elementos arbitrários e imprevisíveis (isto é, da presença de tal ou tal oficial, de um ou outro líder da chamada, do líder do bloco, assim como do estado de espírito de cada um deles). De um lado, ao colocar no banco dos réus aqueles que levaram a cabo as ações criminosas do regime, tais julgamentos admitiam ser possível imputar responsabilidade aos agentes da burocracia nazista; de outro lado, aquela realidade exposta ao júri confirmava que havia uma dimensão de escolha no momento da execução dos crimes. Mas, para Arendt, isso não basta para compreender o que torna alguém um criminoso burocrata, responsável por seus atos e passível de julgamento.

Assim, a primeira observação que devemos fazer acerca do sentido desses crimes, de modo que seja esclarecido o teor da ação e do agente em julgamento, é a de que, segundo Arendt, a responsabilidade pessoal se diferencia da responsabilidade política. Governos e nações podem assumir certos feitos, pelos quais se dizem responsáveis, no sentido político. De certo modo, mesmo os judeus podem ser ditos politicamente responsáveis por não terem sido capazes de dar uma resposta política ao antissemitismo, de maneira a evitar o trágico desfecho trazido pela Solução Final. ${ }^{1}$ Podemos dizer que nos sentimos de alguma forma responsáveis pelos atos de homens e de mulheres que viveram muito antes de nosso próprio nascimento, ainda que tal responsabilidade seja inteiramente discutível. Decerto, cabe perguntar em que sentido podemos dizer que um indivíduo tem realmente responsabilidade "política" por atos como os perpetrados pelo regime nazista.

No terceiro Reich, pelo menos, havia apenas um homem que tomava e podia tomar decisões, tendo assim total responsabilidade política. Esse homem era o próprio Hitler, que certa vez se descreveu, não num ataque de megalomania, mas muito corretamente, como o único homem insubstituível em toda a Alemanha. Todos os demais, que tinham alguma coisa a ver com os assuntos públicos, das posições mais altas às mais baixas, eram de fato dentes de engrenagem, soubessem disso ou não. Isso significa que ninguém mais poderia ser considerado pessoalmente responsável (ARENDT, 2004, p. 92, grifo do autor)?

Sobre o assunto, cf. Bernstein (1996, p. 46-70) e Konh (In: ARENDT, 2016, p. 13-46). 
Se, para Arendt, não há dúvida sobre a responsabilidade política, imputada unicamente a Hitler, cabe questionar se podemos responsabilizar pessoalmente aqueles que obedeceram às ordens criminosas provenientes do regime nazista. Arendt pretende explicar o que é responsabilidade pessoal para então responder a essa pergunta:

[...] apenas num sentido metafórico é que podemos dizer que nos sentimos culpados pelos pecados de nossos pais, de nosso povo ou da humanidade, em suma, por atos que não praticamos. Em termos morais, é tão errado sentir culpa sem ter feito nada quanto sentir isenção de culpa quando se é realmente culpado de alguma coisa (ARENDT, 2004, p. 90, grifos da autora).

Em outras palavras, somente deveríamos atribuir responsabilidade moral ou, ainda, jurídica, por determinada falta aos indivíduos que realmente fizeram alguma coisa de condenável, pois "Não existem coisas como a culpa coletiva ou a inocência coletiva. A culpa e a inocência só fazem sentido se aplicadas aos indivíduos" (ARENDT, 2004, p. 91). Esclarecido o escopo da inocência e da culpa - sempre referidas ao indivíduo que de fato cometeu um ato passível de julgamento - encontramo-nos em condições de discutir a responsabilidade pessoal daqueles que deram suporte ao regime.

Como vimos, um dos traços mais importantes do regime totalitário é o aspecto burocrático de sua estrutura de poder. A burocracia é uma estrutura que transforma os seres humanos em dentes das engrenagens de uma grande máquina. Ora, uma simples peça não pensa ou age por si mesma, pois apenas obedece a uma ordem burocrática e segue uma lei ou decisão superior. Sendo assim, como poderíamos dizer que alguém é responsável por uma ação sob tal regime? O objetivo central do artigo "Responsabilidade pessoal sob a ditadura", publicado em Responsabilidade e Julgamento, é exatamente discutir esse problema:

Em todo sistema burocrático, a transferência de responsabilidades é uma questão de rotina diária, e se desejamos definir a burocracia em termos de ciência política, isto é, como uma forma de governo - o mando dos cargos (the rule of the offices), em oposição ao mando de homens, de um único homem, de poucos ou de muitos -, a burocracia é infelizmente o mando de ninguém e, por essa mesma razão, talvez a forma menos humana e mais cruel de governo. Mas, na sala do tribunal, essas definições não têm serventia. Pois para a resposta: "Não fui eu quem cometeu o crime, mas o sistema no qual eu era um dente de engrenagem", o tribunal imediatamente propõe a seguinte pergunta: "E por que você se tornou um dente de engrenagem ou continuou a sê-lo nessas circunstâncias?" Se o acusado deseja transferir as responsabilidades, ele deve mais uma vez implicar outras pessoas, deve nomeá-las, e essas pessoas aparecem então como possíveis corréus e não como a encarnação da necessidade burocrática ou de qualquer outro tipo. O julgamento de Eichmann, como todos os julgamentos desse tipo, teria sido desprovido de todo interesse se não tivesse transformado o dente de engrenagem ou o "referente" da Seção IV B do Departamento Central de Segurança do Reich num homem. Só por essa operação ter sido realizada com sucesso antes do início do julgamento é que a questão da responsabilidade pessoal, e portanto da culpa legal, pôde realmente surgir (ARENDT, 2004, p. 93-94). 
Como podemos perceber claramente, Arendt recusa o expediente da teoria dos dentes de engrenagem para justificar tais crimes e exige que pensemos qual é a responsabilidade pessoal de um agente da burocracia nazista. Vejamos como podemos compreender tal responsabilidade. ${ }^{2}$

\section{ObedeCER E CONSENTIR}

No relato sobre a banalidade do mal, Arendt argumenta que Eichmann havia tirado a lição errada da obra de Kant. Ao tribunal, o burocrata nazista afirmou ter sido obediente à lei, como prega a filosofia kantiana (cf. ARENDT, 1999, p. 152-167). No entanto, é necessário compreender que tipo de lei ele obedeceu, e por que assim o fez. A autora observa que Eichmann não compreendeu o princípio de reciprocidade implícito no imperativo categórico kantiano. O último não prescreve que devamos obedecer à lei sob quaisquer circunstâncias. Ao contrário, o imperativo "Você deve matar!", por exemplo, não poderia ser considerado uma lei de acordo com qualquer legislação racional, especialmente se as potenciais vítimas não forem criminosas ou pessoas perigosas (o que era o caso dos judeus e de todos os que sofreram perseguição nazista). Por meio da reflexão, sabemos que qualquer

2 Em Origens do Totalitarismo, Arendt analisa a ideologia dos regimes totalitários e a relação destes com a lei. Uma das novidades do totalitarismo é o fato de ter tornado de certo modo obsoleta a divisão entre regimes legítimos e arbitrários, fronteira que permitia o reconhecimento de um regime dito tirânico (sem leis e exercido por um só). O totalitarismo desafia todas as leis positivas (mesmo as que ele próprio produz, como no caso da Constituição Soviética de 1936, ou, ainda, quando acontece de nem se dar ao trabalho de abolir a existente, como no caso da Constituição de Weimar). Isso não significa, porém, que ele opere sem leis, "pois afirma obedecer rigorosa e inequivocamente àquelas leis da Natureza [nazismo] ou da História [stalinismo] que sempre acreditamos serem a origem de todas as leis" (ARENDT, 2012, p. 613). Em outros termos, ao desafiar as leis, o totalitarismo pretende-se ancorado numa forma superior de legitimidade, a qual tem por objetivo "estabelecer diretamente a lei da justiça na terra" (ARENDT, 2012, p. 614). Essa distinção entre legalidade e legitimidade evidencia que o regime totalitário não precisa eliminar as leis, podendo torná-las flexíveis e inoperantes, já que ele tem por base princípios transcendentes, absolutos e inquestionáveis, aplicáveis à humanidade, isto é, sem que isso signifique convertê-los em "critérios de certo e errado que norteiem a conduta individual" (ARENDT, 2012, p. 614). A legalidade e a ilegalidade eram critérios que definiam regimes legítimos e tirânicos, respectivamente. A essência do regime totalitário, porém, é o terror, pois só este garante a realização da lei do movimento, o qual "seleciona os inimigos da humanidade", impedindo, assim, "que qualquer ação livre, de oposição ou de simpatia, interfira com a eliminação do 'inimigo objetivo' da História ou da Natureza, da classe ou da raça. Culpa ou inocência viram conceitos vazios; 'culpado' é quem estorva o caminho do processo natural ou histórico que já emitiu julgamento quanto às 'raças inferiores', quanto a quem é 'indigno de viver', quanto a 'classes agonizantes e povos decadentes'. $\mathrm{O}$ terror manda cumprir esses julgamentos, mas no seu tribunal todos os interessados são subjetivamente inocentes: os assassinados porque nada fizeram contra o regime, e os assassinos porque realmente não assassinaram, mas executaram uma sentença de morte pronunciada por um tribunal superior. Os próprios governantes não afirmam serem justos os sábios, mas apenas executores de leis históricas ou naturais; não aplicam leis, mas executam um movimento segundo a sua lei inerente. O terror é a legalidade quando a lei é a lei do movimento de alguma força sobre-humana, seja a Natureza ou a História" (ARENDT, 2012, p. 618). Quando os criminosos burocratas, não mais sob a égide do regime totalitário, vão a julgamento, essa ideologia deve desaparecer, pois se trata de restabelecer a ideia de consensus iuris, isto é, daquele consentimento básico, que dá origem tanto a povos particulares quanto ao direito internacional, consenso norteador de qualquer julgamento civilizado. Para colocar no banco dos réus o criminoso burocrata, foi preciso recuperar a ideia de legitimidade consentida, segundo a qual pode-se julgar determinada ação de acordo com um critério terreno de justiça. 
permissão para assassinar põe minha vida e a vida de meus pares em perigo. Assim, não posso aceitar essa ordem como um imperativo categórico, prescrito pela razão. Eichmann não era um pensador kantiano, tampouco um bom leitor da filosofia de Kant. Seus crimes são consequência de sua obediência cega à legislação de Hitler. Todas as suas ações contra os judeus eram consequência de uma identificação acrítica com as leis nazistas e com a vontade do Führer, e não o resultado de qualquer reflexão racional autônoma (ARENDT, 1999, p. 153-154). Portanto, ao qualificar a ação de Eichmann - sua contribuição para a Solução Final, um crime contra a humanidade - como banal, Arendt tentava explicar que o crime sob o regime totalitário tornou-se, para tais criminosos, mera rotina burocrática, crime implementado sem repulsa moral ou resistência política. Assim:

[...] deve-se compreender que, embora esses assassinos de massa agissem coerentemente com uma ideologia racista, antissemítica ou pelo menos demográfica, os assassinos e seus cúmplices diretos muito frequentemente não acreditavam nessas justificações ideológicas; para eles, bastava que tudo acontecesse de acordo com a "vontade do Führer", que era a lei do país, e de acordo com as "palavras do Führer", que tinham a força da lei (ARENDT, 2004, p. 105).

Não se tratava, portanto, de compreender o comportamento criminoso daqueles que aderiram de modo convicto ao regime, mas sim daqueles que lhe ofereceram suporte, sem o que o nazismo não poderia ter levado a cabo seu propósito de profilaxia do corpo político e da própria humanidade.

A filósofa conclui ser necessário explicar a articulação entre crime e obediência, ou entre o crime e a incapacidade de pensar por si mesmo, presente no comportamento de um criminoso burocrata, como um expediente para refletir sobre a moralidade. Em A Vida do Espirito, Arendt resume sua posição:

O impulso imediato [por trás de minhas preocupações com as atividades do espírito] derivou do fato de eu ter assistido ao julgamento de Eichmann em Jerusalém. [...] O que me deixou aturdida foi que a conspícua superficialidade do agente tornava impossível retraçar o mal incontestável de seus atos, em suas raízes ou motivos, em quaisquer níveis mais profundos. Os atos eram monstruosos, mas o agente - ao menos aquele que estava agora em julgamento - era bastante comum, banal, e não demoníaco ou monstruoso. Nele não se encontrava sinal de firmes convicções ideológicas ou de motivações especificamente más, e a única característica notória que podia perceber tanto em seu comportamento anterior quanto durante o próprio julgamento e o sumário de culpa que o antecedeu era algo de inteiramente negativo: não era estupidez, mas irreflexão (thoughtlessness) (2002, p. 5-6, grifo da autora).

Eichmann é repreensível por causa de sua falha em criticar a "lei do país" e por sua incapacidade de se afastar das exigências que lhe eram impostas pelo regime. Suas ações criminosas decorrem de sua obediência cega; sua obediência, por sua vez, decorre de seu fracasso em pensar. 


\title{
A SIMPLES OBEDIÊNCIA É CRIME
}

A experiência da obediência, em uma situação política em que a lei é criminosa, em que cometer crimes é exigido por lei ou por ordens superiores, e, ainda, em que agir livremente torna-se ilegal, deve ser analisada com o devido cuidado. Afinal, o que é obediência? Sob uma ditadura moderna, ou, ainda mais, sob um regime totalitário, não temos opções senão ser obedientes? Obedecer é sempre uma exigência política e moral? Aqui, o uso das palavras é importante, porque sob esse uso podemos encontrar significados inesperados.

\begin{abstract}
A obediência é uma virtude política de primeira ordem, sem a qual nenhum corpo político poderia sobreviver. A liberdade irrestrita de consciência não existe em parte alguma, pois significaria a ruína de toda comunidade organizada. Tudo isso soa tão plausível que é preciso algum esforço para detectar a falácia. A sua plausibilidade baseia-se na verdade de que "todos os governos", nas palavras de Madison, mesmo os mais autocráticos, mesmo as tiranias, "baseiam-se em consentimento", e a falácia reside igualar o consentimento à obediência. Um adulto consente onde uma criança obedece; se dizemos que um adulto obedece, ele de fato apoia a organização, a autoridade ou a lei que reivindica "obediência". A falácia é ainda mais perniciosa porque pode alegar uma tradição muito antiga. O nosso uso da palavra "obediência" para todas essas situações estritamente políticas remonta à noção secular de ciência política que, desde Platão e Aristóteles, nos diz que todo corpo político é constituído de governantes e governados, e que os primeiros comandam e os últimos obedecem às ordens (ARENDT, 2004, p. 109, grifo da autora).
\end{abstract}

Quer dizer, a equação que identifica o consentimento à obediência é uma falácia porque infantiliza os membros do corpo político ao transformá-los em objeto de simples mando, eclipsando, assim, a exigência de um verdadeiro consentimento dirigido à organização, à autoridade ou à lei. Um adulto, no sentido kantiano - isto é, aquele que tem a capacidade de pensar por si mesmo e de reconhecer autonomamente a racionalidade da lei, processo que daria sentido ao consentimento - não é obrigado a obedecer a uma ordem criminosa. A pretensa obrigatoriedade da obediência, sem que se mencione o recurso a um verdadeiro consentimento, resultante de uma reflexão autônoma, não é, portanto, uma desculpa para os atos de alguém em tais circunstâncias; ao contrário, a percepção de que obedecer simplesmente, isto é, sem pensar, redunda em uma espécie de consentimento cego, alinhado ao propósito de execução de crimes em massa, leva Arendt a sugerir que a palavra "obediência" deve ser abolida do vocabulário político e moral. Desse modo, poderíamos de fato julgar tais criminosos.

Por isso, a pergunta endereçada àqueles que participaram e obedeceram a ordens nunca deveria ser: "Por que vocês obedeceram?", mas: "Por que vocês apoiaram (Why did you support)?". Essa troca de palavras não é uma irrelevância semântica para aqueles que conhecem a estranha e poderosa influência que simples "palavras" têm sobre a mente dos homens, que são, em primeiro 
lugar, animais falantes. Muito seria ganho se pudéssemos eliminar essa perniciosa palavra, "obediência", de nosso vocabulário moral e político (ARENDT, 2004, p. 111).

Ninguém pode usar a desculpa de ser um mero dente de engrenagem da máquina burocrática para explicar a consecução de um crime. O agente é responsável por suas ações e a influência do regime político pode ser uma circunstância atenuante, a qual deve ser levada em consideração, é claro, como é feito no caso da pobreza, por exemplo. No entanto, enquanto indivíduo, o agente apoia e, assim, suporta tanto o regime quanto os males engendrados por este. Por isso, o agente não é apenas um dente de engrenagem que manifesta por ações uma ordem que provém do alto, atada a uma necessidade natural ou histórica que o ultrapassa.

Arendt está especialmente interessada nesse tipo de criminoso, isto é, naquele que obedece sem resistência. Poderíamos dizer que essa maneira de fazer algo condenável é o que atrai sua atenção. Por essa razão, o estudo do impacto do caso de Eichmann a respeito da obra de Arendt pode de fato nos ajudar a avaliar sua contribuição para as reflexões contemporâneas sobre ética e responsabilidade. A banalidade do mal não é uma teoria ou doutrina, porquanto significa a natureza factual do mal perpetrado por um ser humano incapaz de reflexão - alguém [como Eichmann] que nunca pensou no que estava fazendo, nem durante sua carreira como oficial da Gestapo, responsável pelo transporte dos judeus, nem como um acusado no banco dos réus. Todo o curso do julgamento explicitou e confirmou isso. $\mathrm{O}$ fato bruto da banalidade do mal surpreende e choca porque, como Arendt argumenta, ele contradiz nossas teorias acerca do mal, apontando para algo que, mesmo sendo verdade, não parece plausível. Isso nos obriga a entender que, no mundo moderno, o mal não tem raízes - ele não tem fundamentos ideológicos ou motivos fortes, ele não é perpetrado por monstros, mas sim por tipos simples e comuns, ele não convulsiona em nada a sensibilidade e a inteligência do agente. O mal acontece na superfície de comportamentos diários e corriqueiros. Com efeito, a existência de um regime burocrático desempenha um papel importante aqui, mas tais crimes seriam impossíveis sem o suporte de pessoas incapazes de oferecer resistência à sua perpetração, pessoas que obedecem sem pensar.

\section{NÃO SUPORTAR O MAL}

Em Responsabilidade e Julgamento, Arendt se pergunta: "de que maneira diferiam aqueles poucos que em todas as esferas da vida não colaboraram e recusaram-se a participar na vida pública, embora não pudessem se rebelar e de fato não se rebelaram?" (ARENDT, 2004, p. 106). De acordo com a autora, a resposta à questão é relativamente simples: os não-participantes, aqueles que muitas vezes foram chamados de irresponsáveis, na verdade, foram os únicos que se atreveram a julgar por si mesmos, e foram capazes de fazê-lo não porque dispusessem de um firme sistema de valores ou porque antigos padrões de certo e de errado ainda estivessem plantados em suas consciências. Os não-participantes eram aqueles cujas consciências não funcionavam de modo automático, isto é, como se um conjunto de regras aprendidas ou inatas pudessem ser facilmente aplicadas a casos particu- 
lares, à medida que estes surgissem. O critério dos irresponsáveis era bem diverso de uma normatividade preestabelecida, pois, segundo Arendt, eles se perguntaram até que ponto ainda seriam capazes de viver em paz consigo mesmos depois de terem cometido certas ações exigidas pelo regime nazista. Depois de refletir, eles decidiram que seria melhor nada fazer, não porque o mundo seria então mudado para melhor, mas simplesmente porque só sob essa condição, a de nada fazer, eles poderiam continuar convivendo em paz com sua própria consciência:

[...] eles [os não-participantes] também optavam por morrer quando eram forçados a participar. Em termos francos, recusavam-se a assassinar, não tanto porque ainda se mantinham fiéis ao comando 'Não matarás', mas porque não estavam dispostos a conviver com assassinos - eles próprios (ARENDT, 2004, p. 107). ${ }^{3}$

É importante que Arendt diga que a precondição para esse tipo de julgamento não é o reconhecimento da validade universal de determinados mandamentos morais, ou, ainda, a inteligência ou a sofisticação moral, mas sim a disposição para viver explicitamente consigo mesmo, isto é, para "estar envolvido naquele diálogo silencioso entre mim e mim mesma que, desde Sócrates e Platão, chamamos geralmente de pensar" (ARENDT, 2004, p. 107). Esse tipo de pensamento não é técnico e também não diz respeito a problemas estritamente teóricos. Segundo a autora, a linha divisória entre aqueles que estão dispostos a pensar e, portanto, tentam julgar por si mesmos, e aqueles que não o fazem, ultrapassa todas as diferenças sociais, culturais ou educacionais. Ela diz respeito ao referido diálogo consigo e ao reconhecimento do caráter insuportável da intimidade com um criminoso, atitude que, aos olhos de Arendt, traria consequências negativas ao regime totalitário, pois "só precisamos imaginar por um momento o que aconteceria a qualquer uma dessas formas de governo, se um número suficiente de pessoas agisse 'irresponsavelmente' e se recusasse a apoia-lo, mesmo sem resistência ativa e rebelião, para ver como essa arma poderia ser eficaz" (ARENDT, 2004, p. 110). Não pensar, isto é, obedecer, exige, ao contrário, evitar qualquer diálogo com o malfeitor e, sob essa condição, suportar o mal.

3 Arendt assinala que o totalitarismo foi capaz de afrontar mandamentos que outrora pareciam obrigar moralmente, de modo que se torna patente que todo e qualquer sistema de valores e normas pode ser substituído por novas regras, mesmo aqueles que antes pareceriam inabaláveis: "Pelo que posso ver, há apenas dois dos Dez Mandamentos aos quais ainda nos sentimos obrigados, o "Não matarás" e o "Não prestarás falso testemunho"; e esses dois foram recentemente desafiados com muito sucesso por Hitler e Stálin, respectivamente" (ARENDT, 2004, p. 220). A autora questiona a eficácia de normas morais rígidas para impedir o avanço do tipo de mal em questão ao atestar a mudança de valores produzida pela sociedade alemã, a qual pôde trocar, rapidamente, o "Não matarás" pelo "Sim, matarás". A esse respeito, o colapso moral total da sociedade durante o regime de Hitler mostra que, em tais circunstâncias, aqueles que apreciam valores e se apegam às normas morais não são confiáveis, pois normas e padrões morais podem ser alterados da noite para o dia, e tudo o que fica então é o mero hábito de se agarrar a algo, seja o que for, desde que forneça um guia para a ação. Com certa ironia, a qual parece atingir, inclusive, a moral kantiana, Arendt afirma que muito mais confiáveis do que os que se agarram a normas e padrões são os céticos, porque estes usam a mente para examinar determinada situação e para tirar suas próprias conclusões. 
É preciso salientar, contudo, que em situações extremas, a exemplo da vigência do regime totalitário, a responsabilidade política não pode ser assumida porque esta pressupõe um mínimo de poder político. Há situações em que a única atitude responsável é a de reconhecer a própria impotência (ARENDT, 2003, p. 45). É possível compreender e louvar a atitude dos não-participantes, isto é, daqueles que se recusaram pessoalmente a oferecer suporte ao regime, evitando, assim, os lugares de responsabilidade, onde a obediência e a consequente execução de crimes seriam inevitáveis. Por nada fazer, eles foram bem-sucedidos em evitar o mal, ainda que não estivessem em condições de exercer qualquer resistência política ao regime.

\section{A banalidade do mal}

Em certo sentido, poderíamos dizer que Arendt mudou de ideia sobre o significado do mal trazido à tona pelo nazismo. Em Origens do Totalitarismo, a autora argumenta que este possui um caráter radical, ${ }^{4}$ ao passo que depois de acompanhar o julgamento de Eichmann em Jerusalém, ela conclui que o traço decisivo desse mal é a banalidade. Gerschom Scholem trocou cartas com a filósofa, após a publicação de Eichmann em Jerusalém. Ele apresenta uma crítica à tese de Arendt sobre a banalidade do mal e lhe pergunta por que ela não mais se concentrava no aspecto radical dos crimes nazistas. Como muitos outros, o amigo de Arendt considerou essa ideia ofensiva, pois parecia banalizar não apenas o que Eichmann fizera, mas também o horror do Holocausto. A esta crítica, Arendt responde:

[...] deixe-me vir ao único ponto em que você não me entendeu mal, e onde realmente estou feliz por ter levantado o assunto. Você está certo: eu mudei de ideia e não falei mais do "mal radical". Faz muito tempo que nos encontramos pela última vez, ou talvez já estivéssemos falando sobre esse assunto antes. [...] É realmente minha opinião agora que o mal nunca é "radical", que é apenas extremo e que não possui profundidade nem nenhuma dimensão demoníaca. Ele pode crescer demais e devastar o mundo inteiro, precisamente porque se espalha como um fungo na superfície. É um "desafio ao pensamento", como eu disse, porque o pensamento tenta chegar a alguma profundidade, ir às raízes, $\mathrm{e}$ no momento em que se preocupa com o mal, é frustrado porque não há nada. Esta é a sua "banalidade" (ARENDT, 1978, p. 250-251).

Ora, é importante relembrar que este tema - o mal - é crucial para a análise do declínio do Estado-nação e do fim dos Direitos do Homem, assim como para as análises das condições de vida dos apátridas e de tudo o que pode acontecer a seres humanos, quando estes são despojados do direito a ter direitos, tornando-se, assim, supérfluos. O livro Origens do Totalitarismo narra como o regime produz seres humanos descartáveis, ao se mostrar capaz de obliterar a humanidade de homens e mulheres em sua dignidade. Por causa disso, os

4 Na segunda edição do livro, por exemplo, lê-se: "There is only one thing that seems to be discernible: we may that radical evil has emerged in connection with a system in which all men have become equally superfluous" (ARENDT, 1958, p. 459). 
crimes nazistas podem ser ditos crimes contra a humanidade. Esse é o aspecto radical do mal originado no interior do totalitarismo. R. Bernstein defende, porém, que a banalidade do mal se refere a outro aspecto de tais crimes, hipótese que me parece perfeitamente plausível. Não haveria, assim, contradição entre o que Arendt sugeriu em Origens do Totalitarismo e aquilo que defende sob o impacto do julgamento de Eichmann:

O conceito-chave em sua análise anterior do mal radical era a superfluidade. Depois que testemunhou o julgamento de Eichmann, ela voltou sua atenção para a irreflexão (thoughtlessness). É como se, inicialmente, Arendt tivesse sentido a necessidade de entender algo que não tinha precedentes no mal que entrou em erupção com o advento do totalitarismo do século XX. Sua resposta foi que nunca antes tinha havido uma tentativa sistemática tão completa de mudar a natureza humana, para transformar os seres humanos, na sua pluralidade, espontaneidade e individualidade, em supérfluos. Mas, depois do julgamento de Eichmann, ela ficou preocupada com uma nova e diferente questão: como explicar as "ações monstruosas" cometidas por pessoas que, em outras circunstâncias, pareciam tão "normais" e "comuns" (BERNSTEIN, 1996, p. 152).

Por um lado, o totalitarismo foi capaz de fazer algo sem precedentes: criou uma situação em que inúmeras vidas puderam parecer supérfluas e descartáveis, situação que permitiu os crimes cometidos em campos de concentração e de extermínio. O totalitarismo foi capaz de perpetrar esse mal radical, o de atentar contra a dignidade humana. Por outro lado, os crimes extremos, ou atos monstruosos, foram cometidos, muitas vezes, por pretensos dentes de engrenagens, isto é, por pessoas comuns sem grandes convicções ideológicas ou ódio pessoal, pessoas que eram incapazes de parar a máquina distanciando-se de suas regras. Pessoas que, mesmo em ocasiões em que agiram de modo arbitrário, não eram capazes de verdadeira ação espontânea, tampouco de pensamento autônomo. Obedeceram sem exibir qualquer resistência à ordem vigente, fornecendo, assim, perfeito suporte ao regime. Na superfície desses dentes articulados, encontra-se a banalidade do mal, o qual pôde proliferar-se rapidamente como um fungo. Para dar conta desse segundo aspecto do mal extremo de tais crimes, a banalidade, Arendt criou um conceito, ou seja, reconhecendo a impossibilidade de utilizar um conceito tradicional, ela encontrou um nome para esse novo fenômeno. Mas tal operação, a de dar nomes, já estava em vigor quando a autora forneceu uma das primeiras análises consistentes do totalitarismo - insistindo que se tratava de um evento inédito - e quando ela buscou compreender por que o mal engendrado pelos totalitarismos - o qual deu azo a crimes contra a humanidade - não atingia apenas a grupos determinados, pois seu caráter radical residia no fato de incidir sobre a própria dignidade humana.

\section{REFERÊNCIAS}

ARENDT, Hannah. Eichmann em Jerusalém. Um relato sobre a banalidade do mal. Trad. de José R. Siqueira. São Paulo: Companhia das Letras, 1999. 
. Escritos Judaicos. Organização de Jerome Kohn e Ron H. Feldman. Tradução de Laura D. M. Mascaro, Luciana G. de Oliveira e Thiago D. da Silva. Barueri, SP: Amarilys, 2016.

. Origins of Totalitarianism, 2nd edn. New York: Meridian Books, 1958.

. Origens do Totalitarismo. Antissemitismo, imperialismo, totalitarismo. Trad. de Roberto Raposo. São Paulo: Companhia das Letras, 2012.

. Responsabilidade e Julgamento. Edição de Jerome Kohn. Trad. de R. Einchenberg. São Paulo: Companhia das Letras, 2004.

. A vida do Espírito. O Pensar/ O Querer/ O Julgar, 5. ed. Tradução de A. Abranches, Cesar A. R. de Almeida, H. Martins. Rio de Janeiro: Relume Dumará, 2002.

. The Jew as a Pariah. New York: The Grove Press, 1978.

BERNSTEIN, Richard. Hannah Arendt and the Jewish Question. Cambridge: Polity Press, 1996.

OLIVEIRA, Luciano. 10 lições sobre Hannah Arendt. Petrópolis: Vozes, 2012.

SOUKI, Nadia. Hannah Arendt e a banalidade do mal. Belo Horizonte: UFMG, 2006.

DAdos DA AUTORA

Silvana de Souza Ramos

Doutora em Filosofia pela Universidade de São Paulo. Professora do Departamento de Filosofia da Universidade de São Paulo. São Paulo/SP - Brasil.ramos_si@hotmail.com

Submetido em: 3-4-2017

Aceito em: 7-8-2017

82 Comunicações $\mid$ Piracicaba $\mid$ v. $24 \mid$ n. $2 \mid$ p. 71-82 $\mid$ maio-agosto 2017 